\title{
A usabilidade nos estudos de uso da informação: em cena usuários e sistemas interativos de informação
}

\section{Luciana Ferreira da Costa}

\begin{abstract}
Professora do Departamento de Ciência da Informação da UFPB. Membro do Grupo de Pesquisa Leitura, Organização, Representação, Produção e Uso da Informação e do Grupo de Pesquisa Web, Representação do Conhecimento e Ontologias.
\end{abstract}

Francisca Arruda Ramalho

Professora do Departamento de Ciência da Informação da UFPB. Cordenadora do Grupo de Pesquisa Leitura, Organização, Representação, Produção e Uso da Informação.

Descreve os sistemas interativos de informação pela interface com os usuários da informação, sob a perspectiva da interação homem-computador. Apresenta as origens dos estudos de uso da informação a partir das referências da Ciência da Informação e da Ciência da Computação, expondo as contribuições práticoepistemológicas desses estudos, enfocando a usabilidade. Conclui com a ratificação da necessidade do diálogo interdisciplinar entre esses estudos diante do uso de produtos de tecnologia da informação na sociedade e cultura contemporâneas, apontando campos de interseção.

Palavras-chave: Usuários da informação; Sistemas de informação; Interação homem-computador; Estudos de usuários; Usabilidade. 


\section{The usability in the information use studies: in scene, users and interactive information systems}

The article describes the interactive information systems by way of the interface with information users, under the perspective of the man-computer interaction. It presents the origins of information use studies through references of Information and Computer Science, showing practical and epistemological contributions of user and usability studies. The article is concluded with the ratification of the need of interdisciplinary dialogue between these studies in face of the use of technological products in contemporary society and culture, pointing to intersecting fields

Keywords: Information users; Information systems; Man-computer interaction; Users studies; Usability.

Recebido em 17.07.2009 Aceito em 05.03.2010

\section{Introdução}

Então ocorre alguma mudança na experiência do usuário - a "manipulação direta" do mouse, talvez, ou a resolução da imagem - e de repente ele se sente em casa com a máquina, tão aclimatado ao ambiente que não precisa mais brigar com o software.

Steven Johnson

No fim do último milênio, Castells (2000) afirma que um novo mundo, originado mais ou menos no início da segunda metade do século $X X$, ou seja, no período pós-guerra, tomou forma na coincidência histórica de três processos independentes: a revolução da tecnologia da informação, a crise econômica do capitalismo e do estatismo e a conseqüente reestruturação de ambos e o apogeu de movimentos sociais culturais, tais como libertarismo, direitos humanos, feminismo e ambientalismo. A interação entre tais processos e as reações por eles suscitadas fizeram surgir uma nova estrutura social dominante - a sociedade em rede, uma nova economia - a economia informacional/global e uma nova cultura da virtualidade real - a cibercultura. A partir desse momento, estaríamos vivendo a era da informação.

Essa sociedade em rede da era da informação se caracteriza, segundo Castells, pela predominância das redes de informação e conhecimento em todos os campos da vida social. (CASTELLS, 1999; $2000 ;$ 2001). De acordo com a interpretação desse autor, os grupos adaptam-se de maneira cada vez melhor às novas condições da sociedade 
da informação, utilizando as novas potencialidades abertas pela globalização e pelo acesso às novas tecnologias.

Surgem, cada vez mais, novas formas de ser, agir e pensar dos próprios indivíduos sociais e seus grupos, instituições, quaisquer camadas sociais às quais pertençam, o que constitui, por sua vez, as diversas redes da Era da Informação. As redes transformam as dimensões de tempo e espaço da vida social, seja pela tecnologia ou não ou por sua influência. Pelas redes da contemporaneidade, informações são transmitidas em tempo real e podem-se estabelecer contatos imediatos, independentemente da distância espacial. Chocam-se culturas, identidades, conteúdos informacionais, fundindo-se ou não, reelaborandose, surgem novas possibilidades de aprendizagem, de criação, expressão e inovação humana, compartilham-se saberes, outros são destruídos ou reconstruídos, criam-se novos imaginários, novas tribos, novas estratégias de produção de conhecimento (COSTA; RAMALHO, 2008).

Assim, as redes se tornam possibilitadoras da promoção de geração de conhecimentos e de propagação de suas aplicações através das novas tecnologias e das práticas sociais contemporâneas. Castells (1999) afirma, desse modo, que são tecnologias para agir sobre a informação e não apenas informação para agir sobre a tecnologia.

O progresso das tecnologias da informação e sua capacidade de favorecer à constituição de uma inteligência coletiva, nessa perspectiva, é vista com naturalidade por Levy (2000), fazendo-o afirmar que o domínio dessas tecnologias, agora compreendidas enquanto intelectuais quando utilizadas por essa inteligência coletiva, dá uma vantagem considerável aos grupos e aos contextos humanos que as utilizam, ainda mais quando a sociedade e seus indivíduos em estruturação de redes, redes de comunicação à instauração e vivência de redes de conhecimento. Daí, tem-se em referência a perspectiva cultural da era da informação, ou seja, a compreensão da cultura erigida pelas novas redes sociais, a cibercultura. Para Lemos (2002, p. 282-283), "a cibercultura tem suas raízes no surgimento dos meios de comunicação de massa, mas ganha contornos definidos na atualidade com o computador pessoal, a microeletrônica de massa e as redes telemáticas."

Denominada, por Johnson (2001), de cultura da interface, a cibercultura, na perspectiva de Lévy (1999), é a própria cultura da sociedade contemporânea quando tratamos dos novos espaços virtuais promovidos e constituídos pelas novas tecnologias, ou seja, é a cultura do ciberespaço. A cibercultura, portanto, é a cultura identitária do real ao virtual, é a cultura da interconectividade, da interação em rede, da digitalização, da nova navegação, promotora das mais diversas e complexas redes de informação e comunicação, via novas tecnologias ou por elas influenciadas. Para Johnson (2001), esta seria a cultura em que as novas tecnologias transformam a nossa maneira de criar e comunicar.

Mas o que está por detrás dessas redes na cultura da interface? 0 que as sustenta?

Os sistemas as sustentam. 
Diante dessa resposta, nunca foi tão imperioso compreender/explicar/conhecer/desenvolver a interação entre os sistemas e os indivíduos sociais como nesta sociedade, em rede, da era da informação. Nesse contexto, o relevante papel que se dispõem os estudos de uso da informação se revela. E sob olhar dialógico interdisciplinar entre a Ciência da Informação (CI) e Ciência da Computação (CC), objetivamos apresentar, respectivamente, aqui neste artigo, a partir das referências de cada um desses campos do conhecimento científico social e tecnológico, as contribuições prático-epistemológicas dos estudos de usuários e dos estudos de usabilidade, quando se referem aos estudos dos usuários da informação em relação aos diversos sistemas interativos de informação.

\section{Os sistemas interativos de informação}

Os sistemas se caracterizam por conjuntos de elementos ou componentes que interagem para atingir objetivos (STAIR, 1998).

Os estudos de sistemas evoluíram das ciências da natureza e biológicas aos sistemas humanos e sociais, até aos modernos sistemas tecnológicos, apesar de sua acepção etimológica ter origem na Grécia Antiga sendo utilizada, primeiramente, pelos filósofos pré-socráticos e por Aristóteles.

A partir da compreensão da importância do termo "sistema", em 1968 Von Bertalanffy publicou a obra Teoria Geral dos Sistemas, anunciando uma teoria que se caracterizou enquanto um pensamento que veio a influenciar a ciência nas suas estruturas mais fundamentais. Por essa teoria, tal pensamento foi denominado de sistêmico. O pensamento sistêmico, desta forma, permite uma abordagem epistemológica a qualquer objeto ou fenômeno científico, entendendo-o enquanto um sistema, ou seja, para compreender um objeto ou fenômeno, deve se debruçar sobre as partes que o compõem, suas interações múltiplas, bem como suas funções ou objetivos (VON BERTALANFFY, 1975).

Para Pinheiro (2002), a Teoria Geral de Sistemas ressoa na CI desde as suas origens, principalmente, quando esta trata de redes e sistemas de informação. Vale ressaltar, contudo, que aquela teoria contribuiu para uma visão mecanicista da área da CI, pesando aí críticas ao sistemismo, tendendo à perspectiva mais tecnológica do que a social desta ciência. Da mesma forma, a Teoria Geral dos Sistemas não só ressoa, como está nas bases da construção da CC.

$\mathrm{Na}$ perspectiva dessas duas ciências, incluindo-as no contexto gerencial da Ciência da Administração, Stair (1998, p. 11) define sistema de informação como "uma série de elementos ou componentes interrelacionados que coletam, manipulam e armazenam, disseminam informações." Na atualidade, esse conceito de sistema de informação se aplica inexoravelmente aos meios tecnológicos. Logo, tal conceito foi atrelado ao uso do computador. Constituiu-se, assim, o sistema de informação baseado em computador, conforme Stair, composto por seis elementos: hardware, software, banco de dados, telecomunicações 
(redes), pessoas (usuários) e procedimentos, como descrito em seqüência:

O hardware consiste no equipamento do computador usado para executar as atividades de entrada, processamento e saída. Os dispositivos de entrada incluem o teclado, dispositivos de escaneamento automático, equipamento que pode ler caracteres em tinta magnética e muitos outros dispositivos. Os dispositivos de processamento incluem unidade central de processamento, memória e armazenagem. Há muitos dispositivos de saída, incluindo as impressoras e as telas dos computadores.

O software consiste nos programas e nas instituições dadas ao computador e ao usuário [...].

Um banco de dados é uma coleção organizada de fatos e informações [...].

As telecomunicações permitem ligar os sistemas de computador em verdadeiras redes [...]. As redes podem conectar computadores e equipamentos de computador em um prédio, num país inteiro e no mundo.

As pessoas são o elemento mais importante na maior parte dos sistemas de informação baseados em computador [...].

Os procedimentos incluem as estratégias, políticas, métodos e regras usadas pelo homem para operar o sistema de informação baseado em computador [...] (STAIR, 1998, p.13).

Segundo Pressman (1995, p. 179), os sistemas de informação baseados em computador combinam seus elementos de muitas maneiras com o objetivo final de transformar dados em informação e, numa outra perspectiva convergente à de Stair, acrescenta a documentação enquanto mais um elemento desses sistemas, referindo-se a "manuais, formulários e outras informações descritivas que retratam o uso e/ou operação do sistema". E, sobre as pessoas, Pressman ainda as discrimina em usuários e operadores, estes últimos tanto de hardware quanto de software.

Por tais elementos, os sistemas de informação baseados em computador não só incluem como elemento o próprio homem, como também se disponibilizam enquanto janela de interação da própria máquina com o mesmo. O homem interage com sistemas baseados em computador, conforme afirma Pressman (1995, p. 606), "para realizar melhor, mais rápida, eficiente e precisamente ou menos dispendiosamente" suas tarefas. As tarefas dizem respeito às práticas humanas, incluídas aqui as informacionais, que este já vinha executando manualmente ou por outros modos, considerando-se prática informacional, conforme Araújo (1998), como toda e qualquer ação, seja 
individual ou social, de geração, armazenamento, representação, recuperação, acesso, busca e uso, disseminação, controle, transferência e gestão da informação. Na realidade, um sistema de informação interativo permite que o homem realize as seguintes tarefas genéricas:

Tarefas de comunicação. Atividades que possibilitam que as interações sejam transferidas do produtor para o consumidor.

Tarefas de diálogo. Atividades que o usuário dirija e controle a interação com o sistema baseado em computador.

Tarefas de controle. Atividades que possibilitam que o usuário controle as informações e a cognição por meio das quais outras tarefas genéricas ocorrem (PRESSMAN, 1995, p. 606).

O termo Interação Homem-Computador (IHC), por essa compreensão, surge propondo-se como harmonia na ação exercida, mutuamente, entre dois fenômenos: um humano e outro artificial. A IHC, também denominada Interação Homem-Máquina, caracteriza-se por estudos de pessoas por um lado e sistemas baseados em computadores por outro, incluindo as maneiras como um exerce influência sobre o outro (BARANAUSKAS; ROCHA, 2000).

Para Baranauskas e Rocha (2000), a IHC é um assunto interdisciplinar. Disso decorre a necessidade de contribuição de perspectivas das diferentes disciplinas. O estudo da IHC compreende as áreas da CC, Psicologia, Ciência Cognitiva, Sociologia, Lingüística, Engenharia de Software, entre outras. Seus resultados vêm mostrando procedimentos a serem seguidos para garantir uma ótima comunicação e interação entre usuários e sistemas de informação baseados em computador, a partir de interfaces cada vez mais atraentes e eficientes.

Pressman (1995, p. 608) explica que, desde a década de 1970, as interfaces entre usuários-sistemas foram definidas pela comunicação e interação entre ambos através dos seguintes atributos de interface: janelas (windows), ícones(icons), menus (menus) e dispositivos de indicação (pointing device), associados, desde a última década, com o hipertexto (conjunto de textos estruturados ou organizados dessa forma, e geralmente implementado em meio eletrônico computadorizado, no qual as remissões correspondem a comandos que permitem ao leitor passar diretamente aos elementos associados) e a multitarefa (capacidade de executar uma série de diferentes tarefas simultaneamente a partir do ponto de vista do usuário). De modo específico, a interface que utiliza apenas os primeiros quatro atributos de interface foi denominada de interface baseada em janelas ou WIMP (windows, icons, menus and pointing device), a mais difundida. A interface, portanto, dá-se na utilização do sistema pelo usuário a partir de tais atributos.

Uma instigante reflexão acerca da definição da interface é encontrada em Johnson (2001). O autor adverte que "alguns críticos tendem a achar a definição estreita demais, ou ampla demais [mas que, de maneira geral, a definição acaba se reduzindo às] janelas aponte-eclique e ícones" (JOHNSON, 2001, p. 4-5). E de modo diferente e poético, 
Johnson difere sua definição de interface das definições mais pragmáticas, conforme transcrevemos abaixo:

[...] a interface é na realidade todo o mundo imaginário de alavancas, canos, caldeiras, insetos e pessoas conectados amarrados entre si pelas regras que governam esse pequeno mundo. Isso, para mim, é uma interface em seu modo de arte elevada (JOHNSON, 2001, p. 5).

A interface veio ao mundo sob o manto da eficiência, e está agora emergindo - tal uma crisálida - como forma de arte genuína. Tudo isso em menos de meio século de inovação. Quem pode dizer o que nos espera nos próximos 50 anos? [...] Nossas interfaces são histórias que contamos para nós mesmos para afastar a falta de sentido, palácios de memória construídos de silício e luz. Elas vão continuar a transformar o modo como imaginamos a informação, e, ao fazê-lo irão nos transformar também - para melhor e para pior. Como poderia ser diferente? (JOHNSON, 2001, p. 174).

Por sua vez, de modo profético e instigante, a compreensão de interface futura de Hawking também deve ser destacada:

Dentro de duas décadas, um computador de mil dólares poderá ser tão complexo quanto o cérebro humano. Processadores paralelos poderiam imitar o funcionamento de nosso cérebro e fazer os computadores agirem de forma inteligente e consciente. Implantes neurais poderão permitir uma interface muito mais rápida entre o cérebro e os computadores, eliminando a distância entre a inteligência biológica e a eletrônica (HAWKING, 2002, p. 170).

Acolhendo definições de interface ou mais estreitas ou mais amplas, como as de Pressman, Johnson ou Hawking, o fato é que a interface implica na IHC, na interação usuário-sistema, implica tanto no desempenho do usuário, quando do uso do sistema, quanto na satisfação do próprio usuário. As interfaces modernas tornam a IHC "mais fácil e amistosa, mas somente se um cuidadoso projeto de interface for levado a efeito" (PRESSMAN, 1995, p. 611).

Pressman (1995, p. 611), apoiando-se em Shneiderman (1987), ressalta que toda definição de interface, nesse sentido, "deve iniciar-se com um entendimento dos usuários a que se destina, inclusive perfis de sua idade, sexo, capacidades físicas, educação, background cultural ou étnico, motivação, metas e personalidade." Numa IHC, a interface entre usuários-sistemas parte dos sentidos humanos da visão, do tato e da audição, predominantemente, possibilitando que os usuários de sistema de informação, baseado em computador, recebam as informações (percepção humana dos dados da realidade ou do ambiente), organizemnas na memória (processo mnemônico humano de registro e confronto de 
dados e informações pré-existentes) e as processem (transformação de dados em informações), utilizando-se do raciocínio e da imaginação.

Atualmente, a IHC é um tema em voga, haja vista o crescente e acelerado uso das tecnologias em todo o mundo. A IHC tem sido projetada com fundamento em pesquisas e estudos que tem como foco os fatores humanos, com o objetivo de que sejam desenvolvidas interfaces voltadas às necessidades dos mais variados tipos ou grupos de usuários, que não mais se constituem apenas por usuários de computadores da área de informática, mas sim por usuários domésticos, estudantes, docentes, administradores, políticos, profissionais liberais, entre outros dos mais diversos (DIAS, 2003).

O diagnóstico do perfil e das necessidades dos usuários, com suas características cognitivas, culturais e físicas diferentes, bem como a compreensão das características dos usuários a que se destinam como, por exemplo, idade, sexo, educação, motivação, busca e uso de informação, na interação com os diversos sistemas de informação é, para a CI, tarefa dos Estudos de Usuários. Já para a CC e áreas afins por elas originadas, como a Engenharia de Software e conseqüente Engenharia de Usabilidade, é tarefa dos Estudos de Usabilidade.

\section{Os estudos de usuários}

De acordo com a definição do Novo Dicionário Aurélio Eletrônico da Língua Portuguesa (FERREIRA, 2004), usuário é "aquele que usa ou desfruta algo".

Com o passar do tempo, o termo adquire maior visibilidade em consonância ao que é suscitado pela atual sociedade, considerada sociedade em rede, passando assim a ser definido por autores nacionais e internacionais na vinculação aos estudos de uso da informação. Dessa forma, usuários vêm sendo compreendidos enquanto "aqueles que utilizam, habitualmente, um ou mais serviços da biblioteca" (BUONOCORE, 1963, p. 420), ou "pessoa que utiliza os serviços que pode prestar uma biblioteca, centro de documentação ou arquivo" (SOUSA, 1993, p. 801), ou "indivíduo, grupo ou comunidade favorecido com os serviços da biblioteca, sistemas ou centros de informação e documentação" (MORAIS, 1994, p. 219), ou "aquele indivíduo que necessita de informação para o desenvolvimento de suas atividades" (SANZ CASADO, 1994, p. 19), ou, em síntese, "o elemento fundamental de todos os sistemas de informação" (GUINCHAT; MENOU, 1994, p. 481).

Segundo Currás (1996), cada indivíduo por si só é um caso que requer uma atenção especial. O certo é que não é possível estudar, um a um, todos os indivíduos. Assim, tem-se que reunir pequenos grupos com características similares, como: usuários conhecidos usuários desconhecidos usuários individuais, usuários coletivos, usuários técnicos, usuários particulares, usuários investigadores e usuários técnicoindustriais. Isso corrobora a perspectiva de classificação de usuários em grupos com características aproximadas, segundo o desempenho das suas 
funções sociais, como também proposto por Guinchat e Menou (1994) e Sanz Casado (1994).

Por muito tempo, tentou-se estabelecer categorias de usuários pela pergunta: "informação, para quem?" Entretanto, considerando as várias ocupações dos usuários e seus vários papéis frente à informação, a pergunta, evolutivamente, passou a ser: "informação, para fazer o quê?" Esta última pergunta refere-se ao fato das recentes compreensões de que um indivíduo pode estar incluso em várias categorias de usuários, desempenhando vários papéis nos momentos de sua vida, enquanto um ator social. Vem sendo preferível, assim, perguntar para que se destina a informação e não para quem.

$\mathrm{Na}$ compreensão do usuário da informação, os seus estudos remontam à década de 1940, a partir do trabalho de Bernal e Urquhart, apresentado na Conferência de Informação Científica da Royal Society, bem como de outros trabalhos que vieram contribuir para gerar preocupação para estudos orientados às necessidades dos usuários. Esses estudos consistiam em investigações objetivas que compreendiam a análise das necessidades e dos usos da informação (WILSON, 1981; FERREIRA, 2002; CHOO, 2003).

Para Wilson-Davis (1977), esses estudos passaram a se denominar Estudos de Usuários, referindo-se a quem demanda (ou necessita ou recebe) o que de alguém e para que. É relevante explicar que os termos "quem", "que", "alguém" e "para que" se referem, respectivamente, a usuários, informação, unidades/profissionais/sistemas de informação e finalidade/necessidade de uso da informação.

De acordo com Ferreira (2002), os Estudos de Usuários passaram por diversas e diferentes fases na segunda metade do século $X X$, que apresentamos no QUADRO 1, acrescentando a perspectiva de tais estudos como vêm sendo realizados nessa primeira década do século XXI:

QUADRO 1 - Evolução dos Estudos de Usuários

\begin{tabular}{|c|c|}
\hline DÉCADA & FASES DE EVOLUÇÃO DOS ESTUDOS DE USUÁRIOS \\
\hline $\begin{array}{l}\text { Final da } \\
\text { década de } \\
1940\end{array}$ & $\begin{array}{l}\text { Os Estudos de Usuários tinham como finalidade agilizar e aperfeiçoar serviços e produtos } \\
\text { prestados pelas bibliotecas. Tais estudos eram restritos à área de Ciências Exatas. }\end{array}$ \\
\hline 1950 & $\begin{array}{l}\text { Intensificam-se os estudos acerca do uso da informação entre grupos específicos de } \\
\text { usuários, agora abrangendo as Ciências Aplicadas. }\end{array}$ \\
\hline 1960 & $\begin{array}{l}\text { Os Estudos de Usuários enfatizam agora o comportamento dos usuários; surgem estudos de } \\
\text { fluxo da informação, canais formais e informais. Os tecnólogos e educadores começam a ser } \\
\text { pesquisados. }\end{array}$ \\
\hline 1970 & $\begin{array}{l}\text { Os Estudos de Usuários passam a preocupar-se com mais propriedade com o usuário e a } \\
\text { satisfação de suas necessidades de informação, atendendo outras áreas do conhecimento } \\
\text { como: humanidades, ciências sociais e administrativas. }\end{array}$ \\
\hline 1980 & Os estudos estão voltados à avaliação de satisfação e desempenho \\
\hline 1990 & $\begin{array}{l}\text { Os estudos estão voltados ao comportamento informacional, que define como as pessoas } \\
\text { necessitam /buscam/fornecem/usam a informação em diferentes contextos, incluindo espaço de } \\
\text { trabalho e vida diária. }\end{array}$ \\
\hline $\begin{array}{l}1 \text { a } \text { Década do } \\
\text { Século XXI }\end{array}$ & $\begin{array}{l}\text { Os estudos estão voltados tanto para o comportamento informacional, quanto para a } \\
\text { avaliação de satisfação e desempenho, enfatizando a relação entre usuários e sistemas de } \\
\text { informação interativos, no contexto social das TIC's. }\end{array}$ \\
\hline
\end{tabular}

Fonte: adaptado de FERREIRA (2002). 
O status quo dos Estudos de Usuários vem crescendo desde 1960 na literatura internacional, mediante estudos que analisam os vários e diferentes aspectos de busca e uso da informação, que teve seu crescimento reforçado pela seção especial sobre "Necessidades e Usos da Informação" na publicação da Annual Review of Information Science and Tecnology (ARIST), seção esta iniciada em 1966. Na literatura especializada brasileira sobre a área, os primeiros estudos datam da década de 1970. Contudo, é importante registrar, dada a evolução histórica dos Estudos de Usuários, que o termo apareceu sob outra denominação: "antes ele estava incluído dentro de um grande assunto denominado levantamento bibliotecário" (CUNHA, 1982, p. 6). Foi no início da década de 1960 que o termo Estudos de Usuários começou a ser indexado no Library Literature, onde foram identificadas referências bibliográficas sobre o tema, sendo 293 estudos norte-americanos e 184 estudos de outros países (CUNHA, 1982).

Sanz Casado (1994), inspirado pela metodologia científica, define Estudos de Usuários como "o conjunto de estudos que trata de analisar, qualitativa e quantitativamente, os hábitos de informação dos usuários" sob as diversas abordagens teórico-metodológicas. Assim, apresentamos as abordagens de realização de Estudos de Usuários, pautando-nos em Ferreira (2002, p. 7) e Figueiredo (1979, p. 80), que trabalham essa temática, com bastante propriedade, sob a seguinte perspectiva dual:

1. Abordagem tradicional ou paradigma clássico - estudos direcionados sob a ótica do sistema de informação;

2. Abordagem alternativa ou paradigma moderno - estudos direcionados sob a ótica do usuário.

A abordagem tradicional, como denominada por Ferreira (2002), compreende os estudos sobre como as bibliotecas e os centros de informação são utilizados. Esses estudos concebem o usuário apenas como informante, ou seja, em momento algum é foco do estudo. Tal abordagem não verifica os fatores que ocasionam o encontro do usuário com os sistemas de informação ou o efeito de tal confronto, "limita-se à tarefa de localizar fontes de informação, não levando em consideração as tarefas de interpretação, formulação e aprendizagem envolvidas no processo de busca de informação" (FERREIRA, 2002, p. 3). O aumento no acesso à vasta quantidade de informação requer, entretanto, serviços que se centrem no significado da busca mais do que meramente na localização da fonte, sobretudo, em uma sociedade marcada pelo constante fenômeno informacional e por necessidades informacionais diversificadas, surge a exigência de mudança no paradigma dos sistemas de informação quanto ao seu foco de estudo, para sistemas que dediquem atenção aos estudos dirigidos às necessidades dos usuários (FERREIRA, 2002). Por sua vez, o paradigma clássico denominado por Figueiredo (1999) engloba estudos voltados às organizações (bibliotecas, empresas, governos etc.) e seus sistemas de informação. 
Já a abordagem alternativa compreende os estudos centrados nos usuários. Nesta abordagem o foco é o problema individual de cada usuário, ou seja, o comportamento de busca e uso de informação para satisfação de necessidades. A abordagem alternativa visualiza o usuário em incessante processo de construção, livre para criar o que desejar junto aos sistemas ou aos contextos em que se situam, considerando suas necessidades cognitivas, afetivas e fisiológicas próprias que atuam dentro de esquemas que são parte de um ambiente com restrições socioculturais, políticas e econômicas (FERREIRA, 2002). E sob a denominação de Figueiredo (1999), o paradigma moderno enfatiza o usuário, colocando-o numa posição ativa, fazendo com que as organizações e os sistemas de informação se adaptem às necessidades particulares dos usuários na tentativa de atendê-los.

A abordagem alternativa, ou paradigma moderno, tem sido trabalhada em diferentes vertentes com a finalidade de contribuir com argumentos conceituais e teóricos profundos para esse paradigma em Estudos de Usuários, cujas características principais Miranda (2006) nos apresenta no QUADRO 2. Para a autora citada, existem pontos em comum entre as abordagens, visto que todas elas tendem a isolar o que o usuário percebe como dimensão fundamental de uma situação-problema, bem como o que pode ser expresso por diferentes estratégias cognitivas utilizadas pelos usuários, para especificarem que tipo de informação lhes será útil.

QUADRO 2 -Principais abordagens alternativas

\begin{tabular}{|c|c|c|}
\hline ABORDAGEM & $\begin{array}{l}\text { AUTORES QUE } \\
\text { UTILIZARAM }\end{array}$ & CARACTERÍSTICAS DA ABORDAGEM \\
\hline $\begin{array}{l}\text { Valor } \\
\text { Agregado }\end{array}$ & $\begin{array}{l}\text { Taylor, } \\
\text { MacMullin, Hall, } \\
\text { Ford, Garvey, } \\
\text { Mohr, Paisley, } \\
\text { Farradane }\end{array}$ & $\begin{array}{l}\text { Foco na percepção da utilidade e valor que o usuário traz para o } \\
\text { sistema. Pretende fazer do problema do usuário o foco central, } \\
\text { identificando diferentes classes de problemas e ligando-os aos } \\
\text { diferentes traços que os usuários estão dispostos a valorizar } \\
\text { quando enfrentam problemas. É um trabalho de orientação } \\
\text { cognitiva em processamento da informação. (problema> valores } \\
\text { cognitivos> soluções) }\end{array}$ \\
\hline $\begin{array}{l}\text { Construção de } \\
\text { Sentido }\end{array}$ & $\begin{array}{l}\text { Dervin, Fraser, } \\
\text { Edelstein, } \\
\text { Grunig, Stamm, } \\
\text { Atwood, Palmor, } \\
\text { Palmour, Carter, } \\
\text { Dewdney, } \\
\text { Waner, Chen, } \\
\text { Burger, Hernon }\end{array}$ & $\begin{array}{l}\text { Conjunto de premissas conceituais e teóricas para analisar como } \\
\text { pessoas constroem sentido nos seus mundos e como elas usam a } \\
\text { informação e outros recursos nesse processo. Procura lacunas } \\
\text { cognitivas e de sentido expressas em forma de questões que } \\
\text { podem ser codificadas e generalizadas a partir de dados } \\
\text { diretamente úteis para a prática da comunicação e informação. } \\
\text { (situação > lacuna cognitiva e de sentido > uso) }\end{array}$ \\
\hline $\begin{array}{l}\text { Anomalia } \\
\text { Cognitiva }\end{array}$ & $\begin{array}{l}\text { Belkin, Oddy, } \\
\text { Ofori-Dwumfuo }\end{array}$ & $\begin{array}{l}\text { Foco nas pessoas em situações problemáticas, em visões da } \\
\text { situação como incompletas ou limitas de alguma forma. Usuários } \\
\text { são vistos como tendo um estado de conhecimento anômalo, no } \\
\text { qual é difícil falar ou mesmo reconhecer o que está errado, e } \\
\text { enfrentam lacunas, faltas, incertezas e incoerências, sendo } \\
\text { incapazes de especificar o que é necessário para resolver a } \\
\text { anomalia. } \\
\text { (situação anômala > lacunas cognitiva > estratégias de busca) }\end{array}$ \\
\hline
\end{tabular}

Fonte: MIRANDA (2006, p. 100) 
Noutra perspectiva aproximada a de Miranda (2006), Ferreira (1997, p.12) identifica que a abordagem alternativa tem sido trabalhada em quatro diferentes vertentes na área da $\mathrm{CI}$, como segue:

1. Abordagem de valor agregado, de Robert Taylor (User-Values ou Value-Added);

2. Abordagem do estado de conhecimento anômalo, de Belkin e Oddy (Anomalous States-of- Knowledge);

3. Abordagem do processo construtivista, de Carol Kuhlthau (Constructive Process Approach); e

4. Abordagem Sense-Making, de Brenda Dervin.

Segundo Ferreira, as três primeiras abordagens trazem contribuições conceituais e teóricas para um paradigma alternativo em Estudos de Usuários. Já a Abordagem Sense-Making vai mais além ao apresentar um método para mapear as necessidades de informação sob o ponto de vista do usuário (FERREIRA, 1997).

Não podemos deixar de acrescentar aqui, conforme asseveram Costa, Silva e Ramalho (2009), mais duas abordagens: o modelo de comportamento de busca da informação elaborado por David Elis - com contribuições posteriores de Cox e Hall - e o modelo de busca e uso da informação de Chun Wei Choo. Essas referências são representativas da abordagem alternativa em referência:

Ellis (1989) e Ellis, Cox e Hall (1993) - Modelo de comportamento de busca de informação que parte do pressuposto de que o processo de busca se dá por meio de aspectos cognitivos, constituído por etapas que não acontecem de forma seqüencial, características gerais que não são vistas como etapas de um processo. Inicialmente se baseia em seis categorias de análise: Iniciar, Encadear, Vasculhar, Diferenciar, Monitorar, Extrair. Posteriormente, esse modelo foi aperfeiçoado pelo próprio Ellis em conjunto com Cox e Hall (1993) que acrescentaram mais duas categorias ao modelo original que são: Verificar e Finalizar. [...]

Choo (2003) - Modelo que ressalta três propriedades da busca e do uso da informação: a) o uso da informação é estabelecido a partir do significado que o indivíduo lhe impõe, à luz de suas estruturas emocionais e cognitivas; b) o uso da informação é situacional. $O$ indivíduo faz parte de um meio, profissional ou social, que afeta, diretamente, suas escolhas para o uso da informação e c) o uso da informação é dinâmico, interagindo com os elementos cognitivos, emocionais e situacionais do ambiente, que impulsionam o processo de busca da informação, modificando a percepção do indivíduo em relação ao papel de informação e os critérios pelos quais a informação é julgada. sob um dado assunto. A busca se caracteriza por um processo implementado pelo indivíduo para modificar o estágio anterior (COSTA; SILVA; RAMALHO, 2009, p. 8). 
Figueiredo, ainda, aponta duas vertentes da abordagem alternativa, ou, como ela denomina, do paradigma moderno dos Estudos de Usuários: uma cognitiva e outra holística. A vertente cognitiva se utiliza de pressupostos teórico-metodológicos da Ciência Cognitiva, enfatizando os seguintes processos: "aprendizado, memória, entendimento, solução de problemas, tomada de decisão" (FIGUEIREDO, 1999, p. 15). Por sua vez, a vertente holística "considera não somente os aspectos cognitivos da busca por informação, mas também os aspectos afetivos e psicomotores" (FIGUEIREDO, 1999, p. 15).

Para Baptista e Cunha (2007, p. 173), esses estudos nas últimas décadas ilustram a fase qualitativa dos Estudos de Usuários, utilizando não só teorias de autores já indicados "a exemplos de estudos atuais que empregaram a teoria de Taylor (1982), sense making de Brenda Dervin (1983), Kuhlthau (1999) e [acrescentando também mais recentemente a] usabilidade".

Dessa forma, encerradas, mas não esgotadas as considerações acerca dos Estudos de Usuários, caracterizamos a outra face dos estudos de usuários de sistemas de informação como segue, referindo-nos aos mais recentes Estudos de Usabilidade.

\section{Os Estudos de usabilidade}

De início, engenharia. Engenharia, derivado do latim ingenerare, que significa conceber, planejar, criar, construir. Nunca um termo foi tão disputado à apropriação/denominação prática de suas especializações como a Engenharia na segunda metade do século XX, com exceção da Medicina até os dias atuais.

A recente Engenharia de Usabilidade surge, portanto, como uma nova área de investigação, resultante de uma década e meia de amadurecimento e sistematização das suas pesquisas denominadas de Estudos de Usabilidade, visando direcionar o processo de desenvolvimento da usabilidade de produtos interativos (QUEIROZ, 2001).

Segundo Cybis (2007, p. 17) a Engenharia de Usabilidade emerge como "esforço sistemático das empresas e organizações para desenvolver programas de software interativo com usabilidade". Nesse sentido, ela emerge da Engenharia de Software, que, por sua vez:

[...] é um rebento da engenharia de sistemas e de hardware. Ela abrange um conjunto de três elementos fundamentais métodos, ferramentas e procedimentos - que possibilita ao gerente 0 controle do processo de desenvolvimento do software e oferece ao profissional uma base para a construção de software de alta qualidade produtivamente (PRESSMAN, 1995, p. 31).

$\mathrm{Na}$ literatura da área, encontramos diferentes definições para o termo Engenharia de Usabilidade, sendo que algumas delas foram 
apresentadas por Queiroz (2001), as quais ressaltamos no quadro, em seqüência, que elaboramos:

\section{QUADRO 3 -Definições do termo Engenharia de Usabilidade}

\begin{tabular}{|l|l|}
\hline \multicolumn{1}{|c|}{ AUTORES } & \multicolumn{1}{|c|}{ DEFINIÇÕES DO TERMO ENGENHARIA DE USABILIDADE } \\
\hline Good & $\begin{array}{l}\text { A Engenharia de Usabilidade é uma abordagem empregada no } \\
\text { desenvolvimento de software através da qual a usabilidade de um produto é } \\
\text { especificada em termos quantitativos e esta especificação antecede o processo } \\
\text { de desenvolvimento do produto. }\end{array}$ \\
\hline Tyldesley & $\begin{array}{l}\text { A Engenharia de Usabilidade é o processo através do qual a usabilidade de um } \\
\text { produto é especificada quantitativamente, permitindo que se demonstre se um } \\
\text { produto final atinge ou não os níveis exigidos de usabilidade. }\end{array}$ \\
\hline $\begin{array}{l}\text { Lecerof e } \\
\text { Paternò }\end{array}$ & $\begin{array}{l}\text { A Engenharia de Usabilidade é uma área no domínio da interação usuário- } \\
\text { computador, cujo objetivo essencial é o desenvolvimento de sistemas usáveis a } \\
\text { partir da aplicação, de forma estruturada e sistemática, de diferentes métodos } \\
\text { nos diferentes estágios do projeto e do processo de desenvolvimento, assim } \\
\text { como da integração de iniciativas de avaliação da usabilidade desde os estágios } \\
\text { iniciais do projeto. }\end{array}$ \\
\hline Mayhew & $\begin{array}{l}\text { A Engenharia de Usabilidade é o processo no qual são aplicados métodos } \\
\text { estruturados no projeto de interface usuário-computador visando à usabilidade } \\
\text { do produto final. }\end{array}$ \\
\hline
\end{tabular}

Fonte: adaptado de QUEIROZ (2001).

Segundo Queiroz (2001, p. 47), engenharia de usabilidade é "uma área do conhecimento na qual os pesquisadores e desenvolvedores procuram desenvolver e implementar técnicas que sistematicamente tornem os produtos de software mais usáveis, otimizando os produtos através da otimização do processo". Mas qual a origem e qual a importância desse objeto de estudo da Engenharia da Usabilidade?

Para Pressman (1995), a usabilidade é uma tentativa de se medir a user friendliness enquanto uma medida de qualidade, que, traduzida ao português, significa amigabilidade ao usuário, ou qualidade de ser amigável ao usuário. "Se um programa não for user friendly frequentemente estará destinado ao fracasso, mesmo que as funções que ele execute sejam valiosas" (PRESSMAN, 1995, p. 71).

O termo usabilidade começou a ser usado na década de 1980, como um substituto da expressão user-friendly traduzida para o português, sobretudo nas áreas de Psicologia e Ergonomia. O motivo dessa substituição está na constatação de que os usuários não precisam que as máquinas sejam amigáveis e sim que as mesmas não interfiram nas tarefas que eles desejam realizar. Mesmo porque, um sistema pode ser considerado amigável para um usuário e não tão amigável para outro, tendo em vista que as necessidades diferem de um usuário para outro (DIAS, 2003).

E na diferenciação dos usuários, Pressman (1995, p. 611) os classificam como:

1. Principiantes: sem conhecimento sintático do sistema e pouco conhecimento semântico da aplicação ou uso do computador em geral. 
2. Usuários instruídos e intermitentes: razoável conhecimento semântico da aplicação, mas relativamente pouca lembrança de informações sintáticas para usar a interface.

3. Usuários instruídos e freqüentes: bom conhecimento semântico e sintático, o que frequentemente leva à "síndrome de usuários com poder", ou seja, indivíduos que procuram atalhos e modos abreviados de interação.

Nesse contexto, segundo Pressman (1995) o conhecimento sintático se refere à mecânica de interação exigida para usar a interface com eficiência e o conhecimento semântico se refere a percepção subjacente da aplicação, ou seja, a compreensão das funções que são executadas, do significado das partes, metas e objetivos do sistema.

Trazemos, assim, o pensamento de Dias (2003, p. 29) quando diz que "usabilidade é uma qualidade de uso de um sistema, diretamente associada ao seu contexto operacional e aos diferentes tipos de usuários, tarefas, ambientes físicos e organizacionais". Em outra perspectiva, a autora acrescenta que a usabilidade está ligada, também, desta vez de modo indireto, ao diálogo na interface com a máquina e à capacidade de alcance dos usuários acerca de seus objetivos de interação com o sistema. Ao analisar a usabilidade, podemos afirmar que ao fazê-la pensamos no usuário, no início, no fim e sempre, desde à criação ao desenvolvimento de um sistema, pois a interface entre usuário-sistema implica na usabilidade. Acerca dessa afirmação, lembramos aqui de Moraes (2001, p. 17), quando, tratando da usabilidade de software, explica-nos que:

Usabilidade diz respeito à habilidade do software em permitir que o usuário alcance facilmente suas metas de interação com o sistema. Desta forma, problemas de usabilidade estão relacionados com o diálogo da interface.

A primeira norma internacional que definiu o termo usabilidade foi a International Organization for Standardization (ISO) 9126 publicada no ano de 1991, sobre qualidade de software. Esta norma conceitua a usabilidade "como um conjunto de atributos de software relacionado ao esforço necessário para seu uso e para o julgamento individual de tal uso por determinado conjunto de usuários". Vale ressaltar que embora a norma verse sobre software, suas orientações direcionam também aos sistemas de informação via web.

A norma ISO 9126, em sua parte 1, apresenta as características de qualidade de software:

- Funcionalidade: capacidade do software de prover funções que atendem a necessidades expressas e implícitas, quando usado nas condições especificadas. 
- Confiabilidade: capacidade do software de manter seu nível de desempenho, quando usado nas condições especificas.

- Usabilidade: capacidade do software de ser compreendido, aprendido, usado e apreciado pelo usuário, quando usado nas condições especificadas.

- Eficiência: capacidade do software de operar no nível do desempenho requerido, em relação à quantidade de recursos empregados, quando usado nas condições especificadas.

- Possibilidade de manutenção: capacidade do software de ser modificado. Modificações podem abranger correções, melhorias ou adaptações do software. Mudanças de ambiente ou nas especificações funcionais e de requisitos.

- Portabilidade: capacidade do software de ser transferido de um ambiente a outro.

Essas características nos permitem dizer que o software deve "falar" a língua do usuário com palavras, frases e conceitos familiares, ao invés de termos técnicos relacionados à tecnologia. Os usuários, ao utilizarem um software, não esperam encontrar qualquer tipo de problema nem cometer erros induzidos pela má qualidade do mesmo.

O termo usabilidade, a partir dessa norma, passou a fazer parte de outras áreas do conhecimento, antes limitado principalmente à Ergonomia, tendo como conseqüência, conforme nos lembra Dias (2003), a fundação da Usability Professionals' Association (UPA), constituída por uma comunidade de profissionais, pesquisadores e empresas com participação em pesquisas e testes de usabilidade. Dessa forma, a UPA tem como slogan: "Promovendo conceitos de usabilidade e técnicas wordwildweb" (UPA, 2009).

A partir das pesquisas e discussões da UPA e como evolução da norma ISO 9126, numa perspectiva centrada mais no usuário do que no sistema/produto, surge, então, a ISO 9241, enquanto norma de padrão internacional do estabelecimento de requisitos ergonômicos para trabalho com terminais de visualização.

Este padrão destina-se aos profissionais incumbidos de garantir segurança e efetividade ao trabalho de escritório com computadores. Assim, a promoção da saúde e da segurança dos usuários de computadores são seus objetivos, incluindo também que os usuários operem os equipamentos com eficiência e conforto.

A ISO 9241 está organizada em um conjunto de 17 partes, sendo cada parte referente a diferentes aspectos do trabalho informatizado: Parte 1: Introdução geral; Parte 2: Condução quanto aos requisitos das tarefas; Parte 3: Requisitos dos terminais de vídeo; Parte 4: Requisitos 
dos teclados; Parte 5: Requisitos posturais e do posto de trabalho; Parte 6: Requisitos do ambiente; Parte 7: Requisitos dos terminais de vídeo quanto às reflexões; Parte 8: Requisitos dos terminais de vídeo quanto às cores; Parte 9: Requisitos de dispositivos de entrada, que não sejam os teclados; Parte 10: Princípios de diálogo; Parte 11: Orientações sobre usabilidade; Parte 12: Apresentação da informação; Parte 13: Orientações ao usuário; Parte 14: Diálogos por menu; Parte 15: Diálogos por linguagem de comandos; Parte 16: Diálogos por manipulação direta; e Parte 17: Diálogos por preenchimento de formulário.

Atemo-nos, especificamente, à parte 11 da ISO 9241, que se refere à descrição da usabilidade de sistemas. Essa parte conceitua o termo como "aquelas características que permitem que o usuário alcance seus objetivos e satisfaça suas necessidades dentro de um contexto de utilização determinado." Sublinhamos, com base em Cybis (2003), que esta parte da norma assevera que a usabilidade depende do contexto de uso, que compreende os usuários, as tarefas, o equipamento, bem como os ambientes físico e social capazes de influenciar na usabilidade de um produto. São observados e medidos, ainda, o desempenho e a satisfação dos usuários concernentes à eficácia da interação, eficiência dos recursos alocados e o nível de aceitação do produto pelo usuário. $E$, ainda pela definição de sua parte 11, "usabilidade é a extensão na qual um produto pode ser usado por usuários específicos para alcançar objetivos específicos com efetividade, eficiência e satisfação em um contexto de uso específico".

Como síntese, eis os conceitos da norma em questão:

- Usuário - pessoa que interage com o produto;

- Contexto de uso - usuários, tarefas, equipamentos (hardware, software e materiais), ambiente físico e social em que o produto é usado;

- Eficácia - precisão e completeza com que os usuários atingem objetivos específicos, acessando a informação correta ou gerando os resultados esperados. A precisão é uma característica associada à correspondência entre a qualidade do resultado e o critério especificado, enquanto a completeza é a proporção da quantidadealvo que foi atingida.

- Eficiência - precisão e completeza com que os usuários atingem seus objetivos, em relação à quantidade de recursos gastos.

- Satisfação - conforto e aceitabilidade do produto, medidos por meio de métodos subjetivos e/ou objetivos. As medidas objetivas de satisfação podem se basear na observação do comportamento do usuário (postura e movimento corporal) ou no monitoramento de suas 
respostas fisiológicas. As medidas subjetivas, por sua vez, são produzidas pela quantificação das reações, atitudes e opiniões expressas subjetivamente pelos usuários (ISO 9241-11).

No Brasil, há uma norma específica que segue os conceitos/determinações da ISO 9241. Trata-se da NBR 9241, editada pela Associação Brasileira de Normas Técnicas (ABNT), organismo de normalização nacional associado à ISO. Na NBR 9241, três informações são apontadas para que se possa medir/especificar a usabilidade de forma mais apropriada:

uma descrição dos objetivos pretendidos;

uma descrição dos componentes do contexto de uso, incluindo usuários, tarefas, equipamento e ambientes. Esta pode ser uma descrição de um contexto existente ou uma especificação dos contextos pretendidos. Os aspectos relevantes do contexto e o nível de detalhes requeridos irão depender do escopo das questões apresentadas. A descrição do contexto precisa ser suficientemente detalhada de modo que aqueles aspectos que possam ter uma influência significativa sobre a usabilidade possam ser reproduzidos;

valores reais ou desejados de eficácia, eficiência e satisfação para os contextos pretendidos. [...] (ABNT, 2002, p.4).

Na realidade, a ABNT reproduz a norma da ISO quanto ao conteúdo acerca de usabilidade com, inclusive, a mesma numeração de norma, 9241, por ser a representante brasileira associada internacionalmente à instituição.

De modo complementar, como precursor e reconhecido estudioso da Engenharia da Usabilidade, Jakob Nielsen (1993) defende ser a usabilidade um conceito que busca definir as características de utilização, do desempenho e da satisfação dos usuários, na interação e na leitura das e nas interfaces computacionais, na perspectiva de um bom sistema interativo. Dessa forma, entende a usabilidade como a qualidade que caracteriza o uso de um sistema interativo.

No Prefácio do seu livro Usabilidade na Web: projetando websites com qualidade, Nielsen e Loranger (2007) evidenciam a importância da usabilidade na contemporaneidade:

Há dez anos a Web era algo diferente para as pessoas. Hoje ela é uma rotina, é uma ferramenta. Se for de fácil acesso, elas a utilizarão, do contrário, não. Com dez vezes mais sites e provavelmente centenas de páginas na Web, os usuários estão menos tolerantes a sites complexos. Portanto um projeto falho 
significa negócios perdidos. Nunca a usabilidade foi tão importante.

A usabilidade, assim, garante a própria continuidade e afirmação competitiva de um site, de um software ou de um sistema de informação na perspectiva da interação com o usuário. É pela interação com o usuário, a partir do seu desempenho e da sua satisfação, que se evidencia a sobrevivência de um sistema de informação. Nesse sentido, Nielsen indica que um bom sistema interativo deve proporcionar cinco fatores em relação aos seus usuários: facilidade de aprendizado, eficiência de uso, facilidade de memorização, suporte a erros e satisfação dos usuários.

Com o desenvolvimento dos Estudos de Usabilidade desde a década de 1990, esses cinco fatores de um bom sistema interativo se tornaram referencial de diversos trabalhos/pesquisas da área, sendo identificadas e difundidas por seu idealizador como "os cinco atributos de usabilidade".

$\mathrm{Na}$ realidade, Cybis (2007) adverte que existem diversos atributos, heurísticas, princípios, "regras de ouro", parâmetros ou critérios utilizados nos Estudos de Usabilidade, propostos por diversos autores e instituições nas últimas décadas, a exemplo de Nielsen (1993), Shneiderman e Plaisant (2004), Bastien e Scapin (2007), além da própria norma ISO 9241. Contudo, ressalta o ponto convergente de preocupação de todos:

A construção de um sistema com usabilidade depende da análise cuidadosa dos diversos componentes de seu contexto de uso e da participação ativa do usuário nas decisões de projeto de interface, visto como o processo de configuração de qualidades internas e externas ao sistema (CYBIS, 2007, p. 23).

Desta forma, destacamos os cinco atributos de usabilidade de Nielsen, não por se caracterizarem enquanto as melhores configurações de base para Estudos de Usabilidade, se é que elas existam, entretanto, muito mais pelo autor se apresentar enquanto precursor e reconhecido estudioso da Engenharia da Usabilidade, além da ratificação de seus critérios enquanto uma metodologia amplamente reconhecida nesta área, por sua citação e adoção como metodologia de pesquisa. Mesmo Cybis (2007, p. 23), pesquisador brasileiro, criador e diretor do primeiro laboratório de usabilidade do Brasil, o LabIUtil da Universidade Federal de Santa Catarina (UFSC), considera Jakob Nielsen como "um dos maiores especialistas em usabilidade nos Estados Unidos".

Trazemos, assim, em recomendação, os cinco atributos de usabilidade descritos por Nielsen em seu livro Usability Engineering:

- Facilidade de aprendizado: o sistema deve ser o mais simples possível e de fácil aprendizagem para que o 
usuário tenha a possibilidade de, sem demora, conhecer o sistema e desenvolver suas atividades;

- Eficiência de uso: o sistema deve ser hábil o suficiente para permitir que o usuário, tendo aprendido a interagir com ele, atinja altos níveis de produtividade no desenvolvimento de suas atividades;

- Facilidade de memorização: aptidão do usuário de regressar ao sistema e realizar suas tarefas mesmo tendo estado sem fazer uso dele por um determinado tempo;

- Baixa taxa de erros: em um sistema com poucos índices de erros, o usuário é capaz de realizar suas tarefas sem grandes problemas, recuperando erros, caso aconteçam.

- Satisfação subjetiva: o usuário acha agradável a interação com o sistema e se sente particularmente satisfeito com ele (NIELSEN, 1993, p. 26).

Devemos ressaltar ainda que, diante dos avanços tecnológicos, a usabilidade na web também vem evoluindo. Nesse sentido, Nielsen e Loranger fazem uma recente advertência aos seus critérios de usabilidade, quanto à possibilidade de seu uso, contudo, de maneira agora atualizada:

No início da Web, éramos os únicos a conduzir testes sistemáticos com usuários de sites, assim nossas descobertas iniciais receberam muita atenção e foram amplamente citadas. Isto foi bom, mas tornou-se um problema porque algumas pessoas acreditam que nossas diretrizes não mudaram desde 1994. [...] As diretrizes que desenvolvemos depois de 2000 tendem a ser aplicadas aos estudos que realizamos desde então e, normalmente, apenas as suplementamos com algumas novas que refletem o recente desenvolvimento da Web (NIELSEN; LORANGER, 2007, p. xvii).

Qualquer projeto, pesquisa ou estudo que seja referente à usabilidade com base nos atributos de Jakob Nielsen, portanto, deve suplementar tais atributos com novas referências em face da revolução tecnológica, conforme alerta o autor. Diante dessa revolução, Nielsen e Loranger nos dão a resposta para uma questão que vem a propósito: o que mudou?

O que mudou foi: a tecnologia na Web é mais confiável, e conexões discadas extremamente lentas são cada vez mais raras, portanto, várias diretrizes cujo objetivo era atenuar as restrições técnicas iniciais estão sendo substituídas por diretrizes equivalentes (mas diferentes) que abordam as 
restrições humanas correspondentes. [...] Mas, no geral, a Web melhorou. Agora somos capazes de incluir muitas capturas de tela de designs que funcionam bem. Além disso, a usabilidade medida aumentou substancialmente em termos da rapidez e da maneira como os usuários podem fazer coisas nos Websites. [...] Em outras palavras, o movimento da usabilidade teve resultados mensuráveis em termos da aprimorada experiência do usuário (NIELSEN; LORANGER, 2007, p. xviii-xix).

\section{Considerações Finais}

A necessidade da usabilidade tornou-se exigência enquanto qualidade de uso de sistemas com os quais interagimos cotidianamente e cada vez mais. Seus estudos são imprescindíveis para criação, compreensão e alimentação das redes de comunicação e conhecimento pela IHC na sociedade e cultura contemporâneas. A boa usabilidade implica na promoção de novas relações sóciotécnicas e na sobrevivência de pessoas e instituições, através de: atividades/jogos/simulações interativas; relacionamentos afetivos/pessoais; relações de serviços/comerciais; e/ou relações informacionais/cognitivas. A má usabilidade pode implicar, por sua vez, na construção de imagens ruins de pessoas e instituições, em sua desarticulação/ineficiência ou até falência.

Especificamente no caso do processo de automação de unidades de informação, os avanços tecnológicos, em conformidade com as exigências dos usuários, direcionam para seleção de sistemas de informação baseados em computador com características que permitam a melhor IHC, enquanto integração de qualidade, inferindo-se no desempenho e na satisfação do usuário. Voltando, por conseguinte, aos Estudos de Usuários, se Figueiredo (1999) enfoca que tais estudos objetivam entender as necessidades, preferências e opiniões dos usuários a respeito dos serviços que a eles são oferecidos ou podem vir a ser oferecidos, entende-se, então, que os Estudos de Usabilidade convergem para os Estudos de Usuários, pois ambos tem a preocupação com uma melhor interação do usuário com o sistema e, principalmente, com a satisfação do primeiro e a adequação do segundo.

Por isso, frente à automação cada vez maior das bibliotecas, arquivos, museus, centros e demais unidades de informação, loci reconhecidos de estudo da $\mathrm{CI}$, e da disponibilização de serviços atualmente via web, os Estudos de Usabilidade podem se constituir num forte aliado dos Estudos de Usuários. Se em uma biblioteca, arquivo, museu, centro ou unidade de informação tradicional os Estudos de Usuários estão voltados ao desenvolvimento de pesquisas que permitam conhecer os hábitos das comunidades a que se destinam diante dos seus processos de busca e uso informacional, nas unidades de informação automatizadas os estudos devem ser realizados também desde onde se dá a interação do usuário com os diversos sistemas baseados em computador, atentando à qualidade do seu uso. 
É claro que os Estudos de Usabilidade, por questões de alto financiamento/investimento econômico acerca dos produtos tecnológicos e de sua comercialização através das tecnologias, vem tendendo às aplicações mais coorporativas e comerciais, de maneira diferente dos Estudos de Usuários. Nesse sentido, os Estudos de Usabilidade têm se voltado ao e-commerce, e-government, e-business, jogos de computador, software de gestão, TV digital e, mais recentemente, à interação móvel (de telefones celulares, global positioning systems, pagers, palmtops, laptops, handhelds, wireless devices, até wearables, ou computadores pequenos e leves o bastante para serem usados no corpo do usuário como se fosse uma peça de roupa) (CYBIS, 2007, p. 217-226).

A esse respeito Dias (2003, p. 38) corrobora:

Por essa preocupação crescente com a qualidade e a usabilidade dos produtos oferecidos ao público, vários fornecedores de software intensificaram as inspeções e os testes com usuários em seus programas de avaliação de usabilidade de produtos e sistemas, assim como várias instituições, usuárias da informática, começaram a aplicar esses mesmos métodos de avaliação antes de contratarem novos produtos.

Sendo assim, pelo diálogo entre as CI e CC acerca desses estudos, Bohmerwald (2005) afirma que se uma pesquisa sobre um sistema de informação e seus usuários abordasse características tanto dos Estudos de Usuários quanto dos Estudos de Usabilidade, apontar-se-ia para a convergência de uma análise mais completa. $E$, nessa perspectiva, alguns pesquisadores nacionais da área da Ciência da Informação já vêm contribuindo acerca do fazer dialógico entre os Estudos de Usuários e os Estudos de Usabilidade através da publicação de seus trabalhos como a própria Bohmerwald (2005), além de Paiva e Ramalho (2006), Baptista e Cunha (2007), Ferreira e Pithan (2008), Araújo e Curty (2008), Costa (2008), Costa e Ramalho (2009) e Costa, Silva e Ramalho (2009).

Particularmente, denominamos esse fazer dialógico entre os Estudos de Usuários e os Estudos de Usabilidade como Estudos Híbridos de Uso da Informação. Obviamente, contudo, esse fazer dialógico não vem a ocupar toda a práxis do campo dos Estudos de Usuários, pois outros estudos do comportamento informacional, sob dimensões sociais, educacionais, culturais, econômicas e políticas, não deixarão de existir.

Indicamos, portanto, ao final deste paper, especiais sistemas interativos de informação como campos de interseção dos Estudos Híbridos de Uso da Informação. Entram em cena os aplicativos/software de gerenciamento de recursos informacionais, as bibliotecas digitais, os repositórios digitais temáticos ou institucionais de documentos, os bancos de teses e dissertações, as enciclopédias virtuais, os periódicos eletrônicos, as bases de dados eletrônicas, os portais de informação, etc., vinculando-se a temáticas como arquitetura de informação, ergonomia, 
design centrado no usuário, acessibilidade, portabilidade, funcionalidade, ontologias, web semântica, folksonomia, e isto diante do possível conhecimento e intervenção sobre o desempenho e a satisfação dos usuários quando do uso desses sistemas e seus recursos. Longe de definir aqui essas indicações, apresentamo-las como pistas na promoção da abertura do fazer dialógico em referência.

Dedicando-se, portanto, a compreender o comportamento humano diante de sistemas interativos de informação, os Estudos Híbridos de Uso da Informação podem incorrer/contribuir para o avanço técnico-científicoinformacional e, ao mesmo tempo, para a própria promoção do desenvolvimento humano nesta era da informação.

\section{Referências}

ARAÚJO, E. A. A construção social da informação: práticas informacionais no contexto de Organizações Não-Governamentais/ONGs brasileiras. Brasília: UnB, 1998. 221 f. Tese (Doutorado em Ciência da Informação). Universidade de Brasília, 1998.

ARAUJO, N. C.; CURTY, R. G. Análise da usabilidade de interfaces de repositório institucional: enfoque em uma ferramenta baseada em princípios ergonômicos. In: ENCONTRO NACIONAL DE PESQUISA E PÓSGRADUAÇÃO EM CIÊNCIA DA INFORMAÇÃO, 9., São Paulo, Anais... São Paulo: ENANCIB, 2008.

ASSOCIAÇÃO BRASILEIRA DE NORMAS TÉCNICAS (ABNT). NBR 9241-11. Requisitos ergonômicos para trabalho: orientações sobre usabilidade. São Paulo: Editora Pedagógica e Universitária Ltda, 2002.

BAPTISTA, S. G.; CUNHA, M. B. Estudo de usuários: visão global dos métodos de coleta de dados. Perspectivas em Ciência da Informação, Belo Horizonte, v. 12, n. 2, p. 168-184, mai./ago. 2007.

BARANAUSKAS, M. C. C.; ROCHA, H. V. Design e avaliação de interface homem-computador. São Paulo: UME-USP, 2000.

BASTIEN, C.; SCAPIN, D. RT-0156 - Ergonomic criteria for the evaluation of human-computer interfaces. Rapport technique de I'INRIA. Disponível em: <http://www.inria.fr/rrrt/rt-0156.html>. Acesso em: 09 jun. 2007.

BOHMERWALD, P. Uma proposta metodológica para avaliação de bibliotecas digitais: usabilidade e comportamento de busca por informação na Biblioteca Digital da PUC - Minas. Ciência da Informação, Brasília, DF, v. 34, n.1, p.95-103, jan./abr. 2005.

BUONOCORE, D. Dicionário de bibliotecologia. Santa Fé: Castellvi, 1963.

CASTELLS, M. A era da informação: economia, sociedade e cultura. São Paulo: Paz e Terra, 1999. (A sociedade em rede, v. 1).

A era da informação: economia, sociedade e cultura. $3^{a}$ ed. São Paulo: Paz e Terra, 2001. (O poder da identidade, v. 2). 
A era da informação: economia, sociedade e cultura. $2^{a}$ ed. São Paulo: Paz e Terra, 2000. (Fim de milênio, v. 3).

CHOO, C. W. A organização do conhecimento: como as organizações usam a informação para criar significado, construir conhecimento e tomar decisões. São Paulo: Senac, 2003. cap. 2, p. 63-126.

COSTA, L. F. Usabilidade do Portal de Periódicos da CAPES. João Pessoa: UFPB, 2008. 236f. Dissertação (Curso de Mestrado em Ciência da Informação). Universidade Federal da Paraíba, 2008.

COSTA, L. F.; RAMALHO, F. A. O poder de Mnemósine: a memorização no uso da informação. In: CONGRESSO BRASILEIRO DE BIBLIOTECONOMIA, DOCUMENTAÇÃO E CIÊNCIA DA INFORMAÇÃO, 23., 5 a 8 jul. 2009, Bonito, Anais... Bonito: CBBD, 2009.

COSTA, L. F.; RAMALHO, F. A. Para onde vai a tecnologia? Ensaio social sobre tecnologia, informação e conhecimento. BOCC, Universidade BeiraInterior, Covilhã, Portugal, p. 1-13, abr. 2008.

COSTA, L. F.; SILVA, A. C. P.; RAMALHO, F. A. (Re)visitando os Estudos de Usuário: entre a "tradição" e o "alternativo". DataGramaZero, Rio de Janeiro, v.10, n. 4, p. 1-12, ago. 2009.

CUNHA, M. B. Metodologia para estudos de usuários da informação científica e tecnológica. Rev. Bibliotecon. de Brasília. Brasília, v. 10, n. 2, p. 5-19, jul./dez., 1982.

CURRÁS, E. El usuário de la información. In: TRATADO sobre Ciencias de la Información. Rosário: REUM, 1996. v. 19, cap. 4., p. 364-371.

CYBIS, W. Ergonomia e usabilidade: conhecimentos, métodos e aplicações. São Paulo: Novatec Editora, 2007.

ergonômica.

Manual de Engenharia de Usabilidade: uma abordagem

Florianópolis: LabIUtil, 2003.

DIAS, C. Usabilidade na web: criando portais mais acessíveis. Rio de Janeiro: Alta Books, 2003.

ELLIS, D. A behavioral model for information retrieval system design. Journal of Documentation Science, Cambridge, n.15, p. 237-247, 1989.

ELLIS, D.; COX, D.; HALL, K. A comparison of the information seeking of researchers in the physical and social science. Journal of Documentation, London, v. 49, n. 4, p. 356-369, 1993.

FERREIRA, A. B. H. Novo dicionário Aurélio eletrônico da língua portuguesa versão 5.0. 3a. ed. São Paulo: Positivo, 2004.

FERREIRA, S. M. P. Estudo de necessidades de informação: dos paradigmas tradicionais à abordagem Sense-Making. 1997. Disponível em: <http://www.eca.usp.br/nucleos/sense/index.htm >. Acesso em: 14 jan. 2002. 
Novos paradigmas de informação e novas percepções de usuários. Ciência da Informação, Brasília, DF, v. 25, n.2, p. 217-223, maio/ago. 1996.

FERREIRA, S. M. P.; PITHAN, D. N. Estudos de usuários e de usabilidade na Biblioteca INFOHAB: relato de uma experiência. Disponível em: $<$ http://eprints.org.archive/00011621/01Microsoft Word -

SIDI.2005 FerreiraPithan 15.outubro.pdf>. Acesso em: 20. jan. 2008.

FIGUEIREDO, N. M. Avaliações de coleções e estudos de usuários. Brasília: Associação dos Bibliotecários do Distrito Federal, 1979.

Polis, 1999.

Paradigmas modernos da Ciência da Informação. São Paulo:

GUINCHAT, C.; MENOU, M. Usuários. In:

- Introdução geral às técnicas da informação e da documentação. Brasília: IBICT, 1994. p. 481491.

HAWKING, S. O universo numa casca de noz. São Paulo: Arx, 2002.

INTERNATIONAL ORGANIZATION FOR STANDARDIZATION (ISO). ISO 9241. Ergonomic requeriments for office work with visual display terminals. Genève, 1998.

. ISO 9126. Software product evoluation: quality characteristics and guidelines for their use. Genève, 1991.

JOHNSON, S. Cultura da interface: como o computador transforma nossa maneira de criar e comunicar. Rio de Janeiro: Jorge Zahar, 2001.

KUHLTHAU, Carol. The role of experience in the information search process of an early career information worker: perceptions of uncertainty, complexity, construction and sources. Journal of the American Society of Information Science, v. 50, n. 5, p. 399-412, 1999.

LEMOS, A. Cibercultura: tecnologia e vida social na cultura. Porto Alegre: Sulina, 2002.

LÉVY, P. A inteligência coletiva: por uma antropologia do ciberespaço. $3^{a}$ ed. São Paulo: Loyola, 2000. . Cibercultura. São Paulo: Ed. 34, 1999.

MIRANDA, S. V. Como as necessidades de informação podem se relacionar com as competências informacionais. Ciência da Informação, Brasília, v. 35, n. 3, p. 99-114, set./dez. 2006.

MORAIS, C. Usuários de bibliotecas: informação x cidadão comum. Biblios, Rio Grande, v. 6, p. 219-223, 1994.

MORAES, D. O concreto e o virtual: mídia, cultura e tecnologia. Rio de Janeiro: DP\&A, 2001.

NIELSEN, J. Changes in web usability since 1994. Dec. 1997. Disponível em: <http://www.useit.com/alertbox/9712a.html>. Acesso em: 18 nov. 2007. 
. Usability engineering. San Diego: Academic Press, 1993.

NIELSEN, J.; LORANGER, H. Usabilidade na web: projetando websites com qualidade. Rio de Janeiro: Campus, 2007.

PAIVA, E. B.; RAMALHO, F. A. Usabilidade de software: um estudo com bibliotecas universitárias do nordeste brasileiro. In: SEMINÁRIO NACIONAL DE BIBLIOTECAS UNIVERSITÁRIAS, 14., 22 a 27 out. 2006, Salvador. Anais... Salvador: SNBU, 2006.

PINHEIRO, L. V. R. Gênese da Ciência da Informação ou sinais anunciadores da nova área. In: AQUINO, M. (Org.). O campo da Ciência da Informação: gênese, conexões e especificidades. João Pessoa: Editora da UFPB, 2002, p. 61-85.

PRESSMAN, R. S. Engenharia de software. São Paulo: Markron Books, 1995.

QUEIROZ, J. E. Abordagem híbrida para a avaliação da usabilidade de interfaces com o usuário. 2001. 410f. Tese (Doutorado em Engenharia Elétrica). Universidade Federal da Paraíba, Campina Grande, 2001.

SANZ CASADO, E. Manual de estudios de usuarios. Madrid: Pirâmide, 1994.

SHNEIDERMAN, B. Design for computer systems. [s.I.]: Addison-Wesley, 1987.

SHNEIDERMAN, B.; PLAISANT, C. Design the user interface: strategies for effective human-computer interaction. 4 ed. [s.l.]: Addison-Wesley, 2004.

SOUSA, J. M. Dicionário de bibliotecología y ciencias afines. 2.ed. Madrid: Fundación Germán Sánchez Rui Pérez, 1993.

STAIR, R. M. Princípios de sistemas de informação: uma abordagem gerencial. 2 ed. Rio de Janeiro: LTC, 1998.

USABILITY PROFESSIONALS' ASSOCIATION (UPA). Site oficial. Disponível em: < http://www.upassoc.org/about upa/index.html>. Acesso em: 20 jun. 2009.

VON BERTALANFFY, L. Teoria geral dos sistemas. Petrópolis: Vozes/MEC, 1975.

WILSON, T. D. Recent trends in users studies: action research and qualitative methods. Disponível em: <http://www.shef.ac.uk/ ispublications/inpres/paper.76html>. Acesso em: 18 mar. de 2000.

WILSON-DAVIS, K. The center for research on users studies: aims and functions. Aslib Proceedings, v. 29, n. 2, p. 67-76, 1977. 